\title{
Examining the spatio-temporal evolution and characteristics of large-scale European droughts
}

\author{
Simon Parry ${ }^{1}$, Christel Prudhomme ${ }^{1}$, Jamie Hannaford ${ }^{1}$ and Ben Lloyd-Hughes ${ }^{2}$
}

${ }^{1}$ NERC Centre for EcologyWallingford, UK; ${ }^{2}$ Walker Institute, University of Reading, UK

Email:spar@ceh.ac.uk

\begin{abstract}
Historical records of major droughts at continental scales are useful in contributing to improved water resources management and better understanding of hydrological processes. Droughts exhibit complex spatial and temporal variability, so an objective classification is preferable to allow comparisons between different regions and seasons. This study investigates the use of thresholdbased regional indices of hydrological and meteorological deficiency to characterise regional drought across Europe, and to examine the spatio-temporal evolution of large-scale droughts. Major droughts over the second half of the twentieth century have been identified using these approaches, and the 1962-64 and 1995-97 events are explored in more detail, with particular focus on the UK, through comparisons between their differing spatio-temporal evolution, temperature and pressure anomalies and the synoptic climatic conditions. It is concluded that the European droughts of 1962-64 and 1995-97 have distinctive 'signatures', and a variety of drought characteristics and developmental stages that reflect the complexity of drought evolution. Whilst the former event featured a straightforward succession of dry winters that were generally coherent in the UK and Europe, the latter was a more complicated amalgam of summer and winter deficiencies containing alternating periods when the UK was 'in phase' or 'out of phase' with Europe. These complexities potentially preclude the development of forecasting tools pending further research on the intricacies of the spatio-temporal variability of droughts.
\end{abstract}

\section{Introduction}

Drought is a complex phenomenon which varies spatially and temporally in its extent, duration, frequency and severity. As such, in drought charactersiation studies, an objective methodology that identifies deficit conditions relative to the season and the location under consideration is preferable, in order to facilitate intercomparison between drought episodes across spatial and temporal scales. Previous studies have produced objectively-defined drought catalogues for Europe (Lloyd-Hughes et al., 2010) that have allowed an assessment of the spatial coherence of droughts, as well as regional analyses of drought characteristics (Hannaford et al., in press). Summaries of the major large-scale European droughts of the last 50 years have been derived from these catalogues (Parry et al., 2010), and it is these analyses that are presented here.

This paper presents data and qualitative information on two major droughts that complement the quantitative approaches documented in Hannaford et al. (in press). The use of supplementary qualitative information is effective in highlighting commonalities between drought events on a European scale, especially important given the lack of statistical significance indicated by quantitative analyses (Hannaford et al. in press), with low correlations between drought occurrence in different regions inhibiting the development of forecasting tools based on deficit conditions in neighbouring areas. Statistical approaches were applied to long timeseries of drought indices, incorporating 'drought poor’ periods which may mask common patterns within individual events. The drought summaries will help in answering questions related to the spatio-temporal evolution of the major European droughts, the identification of common patterns of drought onset and progression, and any potential and/or consistent time lags in drought development which may inform the creation of monitoring or forecasting tools for the UK and Europe.

Whilst previous studies have investigated spatiotemporal drought evolution, such research has been constrained by the period over which data were available. Zaidman et al. (2002) characterise the spatio-temporal behaviour of the 1975-76 and 1989-90 droughts, but their analysis of data spanning 1960-1995 omits three more recent significant drought episodes. Similarly, whilst Briffa et al. (1994) examine a much longer period (1892-1991), there is a need to extend their study of the spatial and temporal details of drought to incorporate the significant drought events witnessed over the last 20 years. Briffa et al. (1994) also restrict their consideration of drought to the three summer months (June - August); there is a need to objectively identify deficit conditions occurring in different seasons, which can often be just as, if not more, important than summer deficiencies for the water resources outlook, particularly for the UK. Whilst the 1975-76 and the 2003 events in particular have been covered extensively in the literature (e.g. Davies, 1978; Doornkamp et al., 1978; Fink et al., 2004; Marsh, 2004), this paper focuses on the less well-documented droughts of 1962-64 and 1995-97. Both quantitative and qualitative investigations of the spatio-temporal development of early-mid twentieth century drought events are few and far between in the literature, and there are fewer sources of information in general on European drought prior to the 1975-76 event.

This paper outlines the methodology and data used, then briefly discusses how major pan-European events have been identified, before presenting qualitative analyses of 
the spatio-temporal evolution, temperature and pressure anomalies and the synoptic climatic conditions of the 1962 64 and 1995-97 European droughts. The paper concludes with a brief discussion of the implications of this study.

\section{Methodology}

The drought catalogues (Lloyd-Hughes et al., 2010) and the subsequent analyses presented here use a parallel classification of hydrological and meteorological drought indices. Hydrological drought is measured using the Regional Deficiency Index (RDI; Stahl and Demuth, 2001) as a method for characterising drought within homogeneous regions. Daily river flow timeseries are converted into binaries based on whether the flow falls below a daily-varying Q90 threshold; ' 1 ' if the flow is below the threshold, and ' 0 ' otherwise. The homogeneous regions are then produced through a cluster analysis on these binary timeseries, grouping catchments of similar drought occurrence. Finally, the arithmetic mean of the binary deficit indices within each homogeneous region is taken, producing a daily timeseries of values between 0 and 1 reflecting the measure of spatial coherence, and by proxy the severity, of drought on a regional basis. The homogeneous regions used in producing the drought catalogue and within this study, as shown in Figure 1, are taken from Stahl and Demuth (2001), although modifications were made to the French (Prudhomme and Sauquet, 2006) and the UK regions (Hannaford et al., in press). Meteorological drought is expressed through the Regional Standardised Precipitation
Index (RSPI), a modification of the Standardised Precipitation Index (SPI; McKee et al., 1993). The RSPI facilitates comparison of meteorological drought occurrence across the spectrum of rainfall regimes, and is derived by calculating the proportion of cells that are 'in drought' within the homogeneous regions. It should be noted that although the $\mathrm{RDI}$ is a daily index of drought occurrence, where the RDI is presented in this study it has been aggregated to the monthly time step to facilitate intercomparison with the monthly RSPI. Further information on the methodologies employed can be found in Hannaford et al. (in press).

In assessing the 1962-64 and the 1995-97 droughts, several approaches have been utilised. The qualitative narratives of spatio-temporal development were summarised from drought matrices and monthly evolution maps. The drought matrices display monthly-averaged RDI values for a subset of European regions, those areas whose drought characteristics were most closely correlated with those of the UK regions (Hannaford et al., in press). These matrices help to summarise a vast amount of information displayed in the monthly evolution maps into a succinct table for each event, providing an overview of the spatio-temporal evolution of the major drought events. A number of monthly evolution maps have been selected for each of the events that best represent the defining spatio-temporal characteristics of the episode. The parallel presentation of both the RSPI and RDI allows for analysis of potential time lags between the relative onset of meteorological and hydrological drought.

Qualitative patterns in temperature and pressure anomalies prior to and during drought events were considered

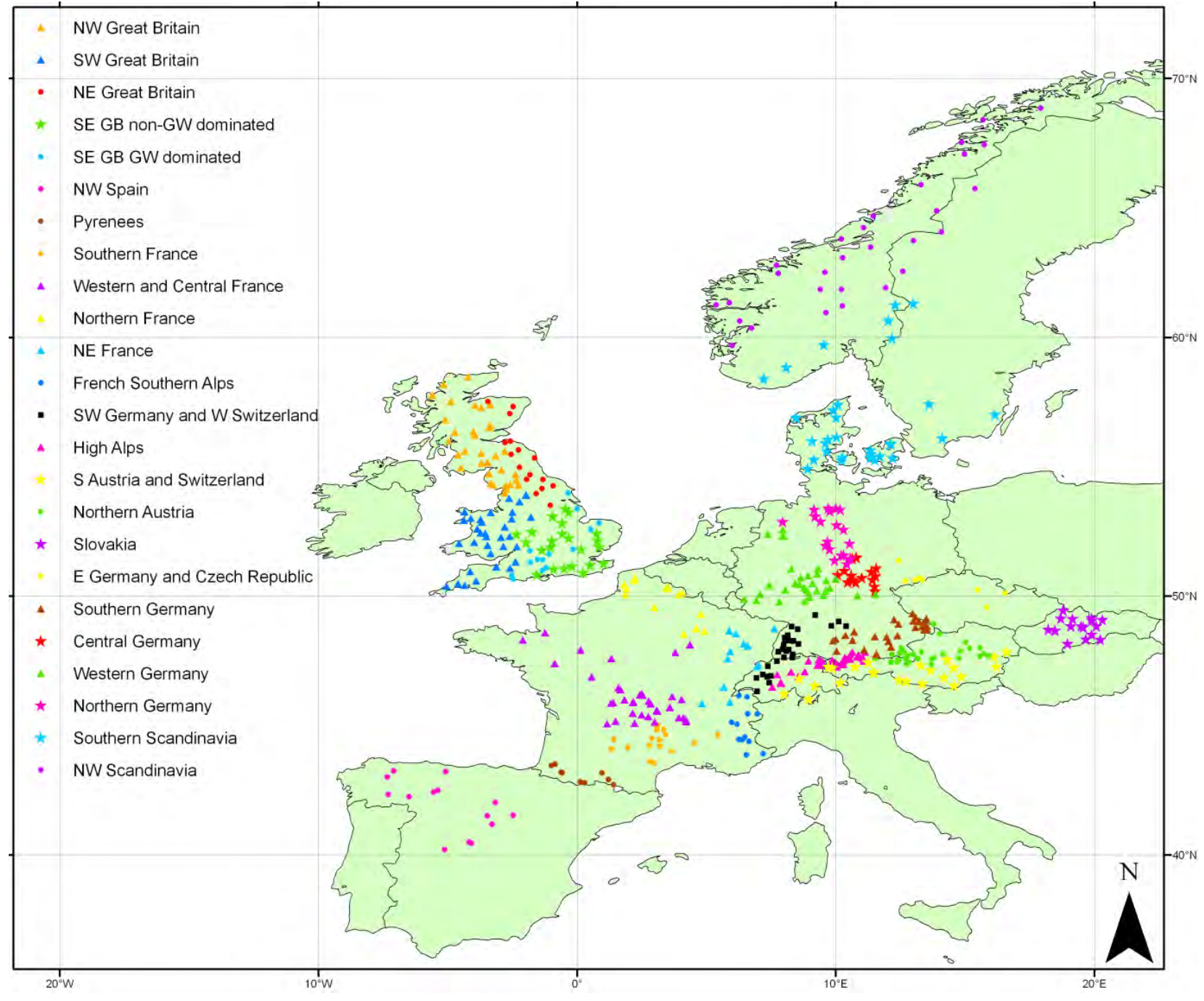

Figure 1 Homogeneous drought regions for Europe (Stahl and Demuth, 2001; Prudhomme and Sauquet, 2006; Hannaford et al. in press). 
in assessing possible drivers for spatially coherent episodes on a European scale. Extreme temperature anomalies, influenced by the synoptic climatic conditions and associated pressure anomalies, often have the effect of reducing the amount of precipitation which can enter the hydrological network, either through evaporation of rainfall which then must be replaced before precipitation can sustain river flows, or through the locking up of water destined for the hydrological network in snowpacks or frozen ground.

\section{Data}

To characterise hydrological drought, daily river flow data from 579 gauging stations spanning 11 European countries from the European Water Archive (EWA) are utilised, updated to cover the period 1961-2005 by Stahl et al. (2008) and supplemented by additional stations sourced from Banque Hydro (France) and the National River Flow Archive (UK). The dataset comprises catchments with minimal artificial influences, considered to be 'near-natural', and the associated gauging stations have good hydrometric performance. The distribution and density of gauging stations across the continent is highly variable, owing predominantly to the necessity for minimally influenced catchments.

For meteorological drought definition, $0.5^{\circ} \times 0.5^{\circ}$ gridded monthly precipitation data from the Climate Research Unit (CRU) (Mitchell and Jones, 2005) are used.

\section{Selection of major drought events}

The production of drought catalogues (Lloyd-Hughes et al., 2010) using a consistent objective methodology allowed for regional intercomparison of drought occurrence and characteristics across the continent. Figure 2 shows the RDI timeseries for the period 1961-2005 for all 24 of the European regions.
Figure 2 highlights distinct 'drought rich' and 'drought poor' periods on a European scale. This suggests that there is often a good degree of spatial coherence in drought occurrence on a continental scale for the most significant events. The 'drought rich' periods generally correspond to periods which have been widely reported in the literature as important droughts on a European scale; the droughts of 1962-64, 1975-76, 1988-92, 1995-97, and 2003 appear clearly. It should be noted that a significant multi-year drought occurred in the UK from 2004-06, but this has been omitted from analysis due to data limitations.

\section{The 1962-64 Drought}

\section{Spatio-temporal evolution}

The 1962-64 drought can be characterised as two successive winter droughts punctuated by dry summers on the continent (Figure 3). Streamflow drought developed gradually, beginning in summer 1962 across France and Alpine Europe, increasing in severity through the autumn across central Europe (see Oct 1962 map in Figure 4). Deficits further intensified throughout winter 1962/63, affecting the majority of central Europe and encompassing parts of northern Europe and Scandinavia, peaking in severity in January and February (see Feb 1963 map in Figure 4) during which month Germany experienced RDI values in excess of 0.9 . In the UK, the winter of 1962/63 was extremely cold, with frozen catchments generating historically low winter runoff rates, particularly in northern areas (see Figure 3). The cessation of drought throughout the remainder of 1963 can be attributed to changing synoptic conditions, with the prevalence of cyclonic conditions in the spring in the UK and Europe causing significant snowmelt which sustained river flows.

A second successive winter drought followed in 1963/64 across western and central Europe, with Germany once again witnessing the most coherent deficits (see Jan



Figure 2 RDI timeseries for all regions, 1961-2005. 


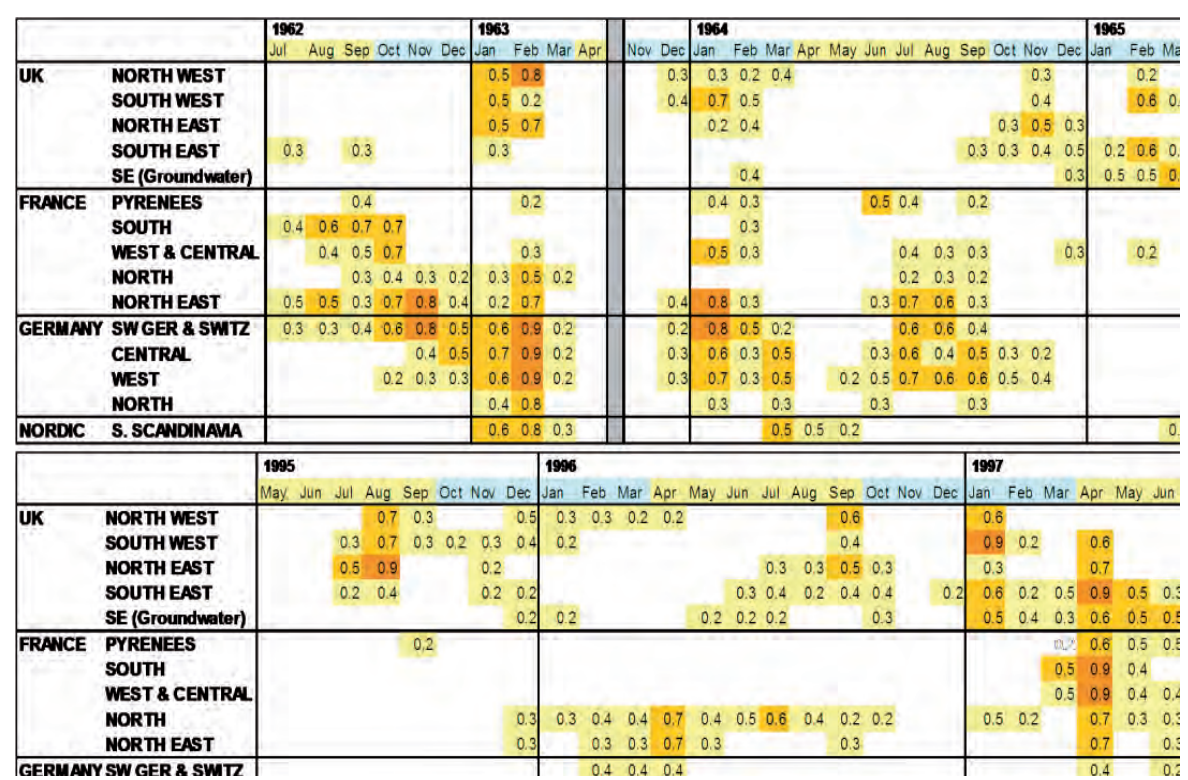

Figure 3 Drought matrices for the 1962-64 and the 1995-97 droughts.

\begin{tabular}{|ll|l|l|l|l|l|l|l|l|l}
\hline $\mathrm{RDI}>0.2$ & $\mathrm{RDI}>0.5$ & $\mathrm{RDI}>0.8$
\end{tabular}

\section{2-64 Drought}

\section{Rainfall - RSPI River Flow - RDI}
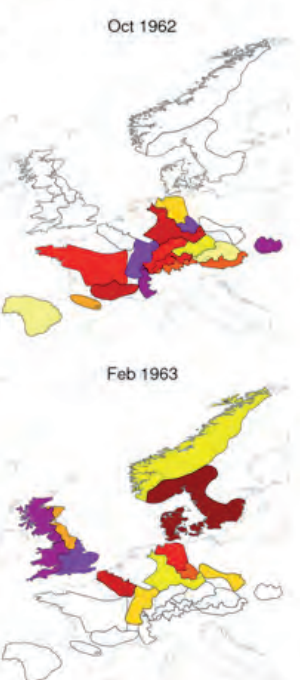

Jan 1964

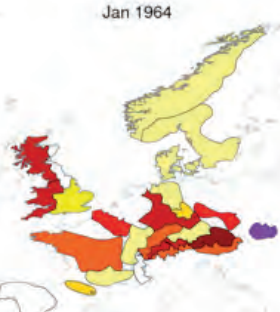

Jul 1964

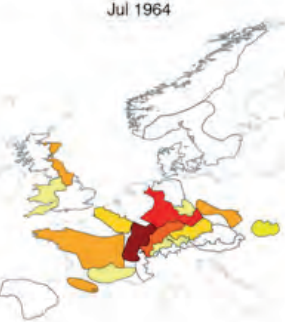

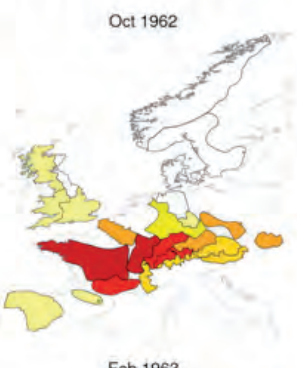

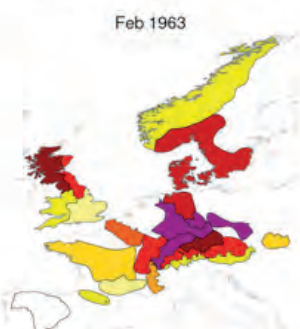

Jan 1964

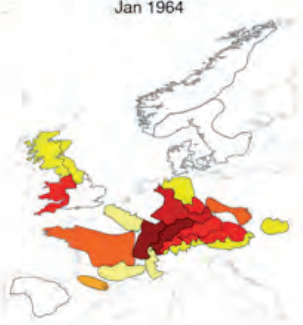

Jul 1964

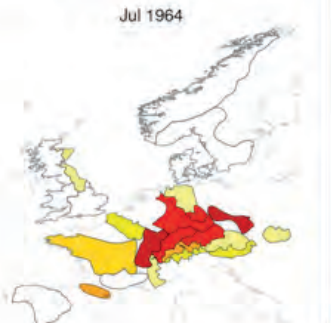

1995-97 Drought

\section{Rainfall - RSPI River Flow - RDI}
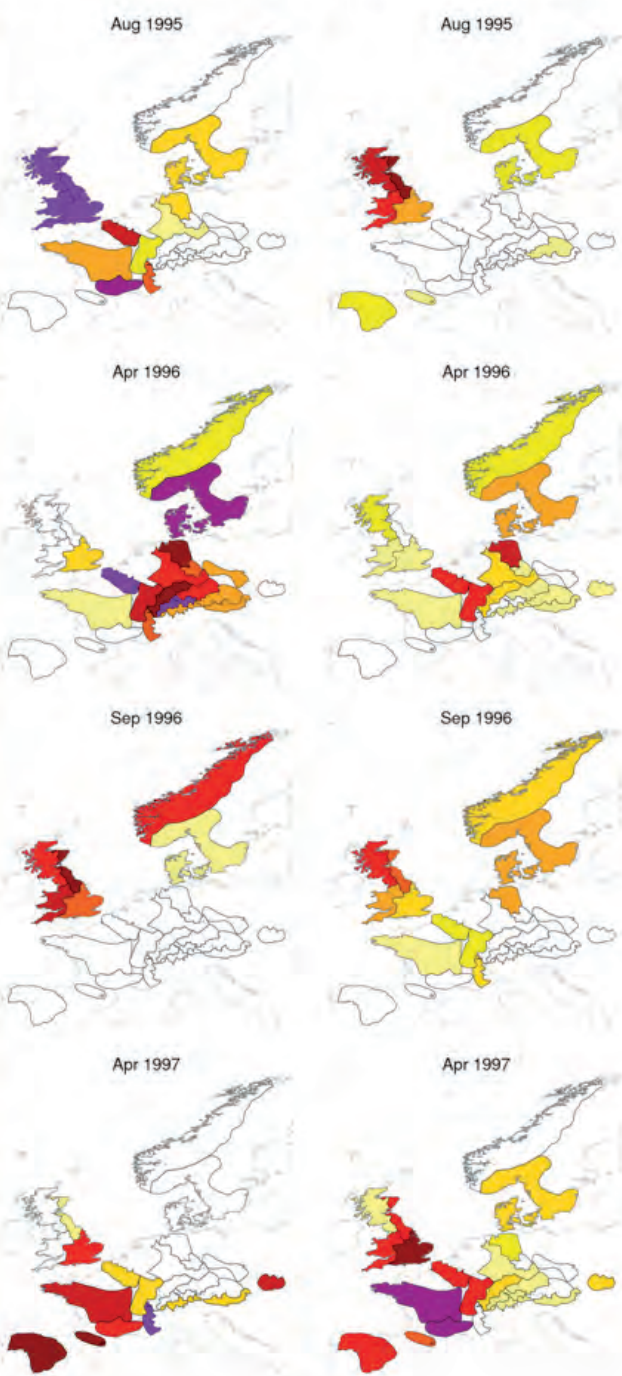

Figure 4 Spatio-temporal evolution maps for the 1962-64 and the 1995-97 droughts. 
1964 map in Figure 4). In the UK, the worst of the winter deficits were confined to south-west areas, and although the drought was less coherent than the previous winter throughout the British Isles, it was longer. Akin to the winter 1962/63 phase, drought conditions in winter 1963/64 also receded rapidly in the spring, on this occasion into northern Germany and Scandinavia (see Figure 3). However, streamflow deficiencies did not abate for long; a moderately coherent summer drought affected France, Germany and Alpine areas (see Jul 1964 map in Figure 4), although this was not persistent through the autumn of 1964. Although the winter of 1964/65 was relatively dry, deficits were not coherent: a third consecutive winter drought predominantly affected the UK, developing during the autumn in eastern regions and intensifying toward winter 1964/65, peaking in February 1965 with moderately coherent RDI values of 0.6.

Although major drought events incorporating a succession of winter deficits are often the most significant from a streamflow deficiency and water resources viewpoint, the 1962-64 drought in the UK was of limited hydrological significance (Cole and Marsh, 2006), which can be attributed to the considerably wet springs that followed each winter period. Similarly, although the winters of 1963/64 and 1962/63 rank as the first and second driest on record, respectively, since 1914 for England and Wales, significant streamflow drought was mitigated through the buffering effect of groundwater against meteorological deficiencies, as groundwater levels were replenished between the dry winters. Zaidman and Rees (2000) did find some hydrological response, noting that 1963 and 1964 were second and fourth, respectively, in a list ranking years by the number of stations registering period of record (1960-95) minimum flows. Nevertheless, despite the perhaps limited

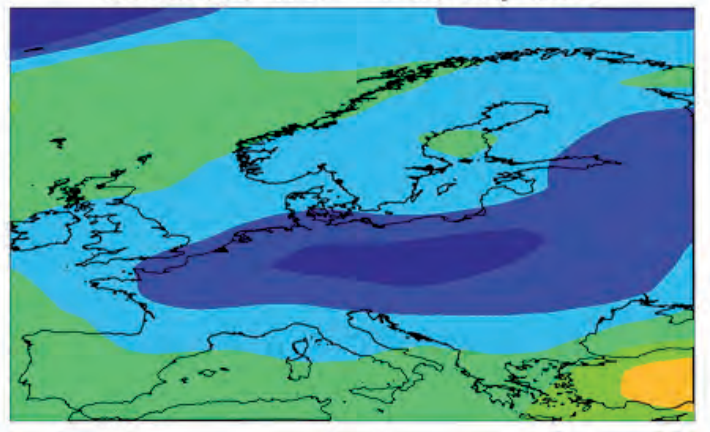

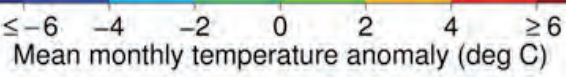

June 1962 - July 1965

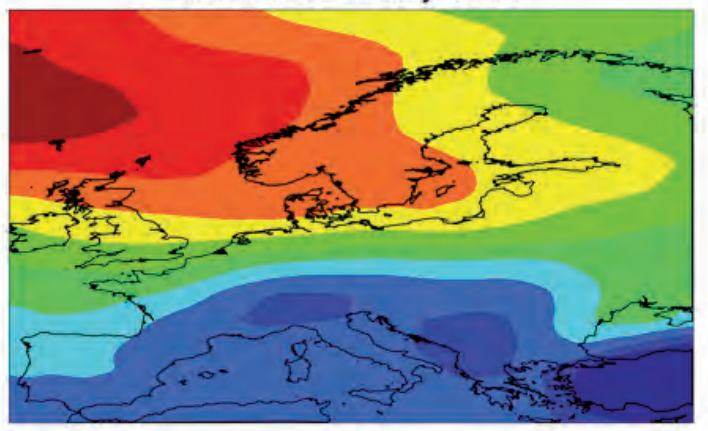

$\begin{array}{lcccc}\leq-2 & -1 & 0 & 1 & \geq 2 \\ \text { Mean monthly surface } & \text { pressure anomaly }(\mathrm{mb})\end{array}$ hydrological expression of the 1962/64 drought, the potential impact of successive winter drought phases was not lost on water resources managers, particularly at a time of rapidly increasing water demand. The 1962-64 drought triggered the design and construction of many of the major reservoirs in the UK.

\section{Temperature and pressure anomalies}

The 1962-64 drought began in spectacular fashion, and the winter of 1962/63 remains one of the worst witnessed in Europe in the last 50 years. Abnormally high pressure anomalies over the North Atlantic (Figure 5) suppressed precipitation for much of the two years that followed, although these blocking anticyclonic conditions were punctuated by periods which allowed greater amounts of precipitation. This is represented by the lack of spatially coherent deficit conditions which developed during the 1962 64 drought. Towards the end of the drought, the blocking anticyclonic conditions migrated east from their predominant position over the North Atlantic, further suppressing rainfall over Europe.

\section{Synoptic climatic conditions}

The high pressure system that persisted over the North Atlantic throughout much of the 1962-64 drought is associated with the pronounced negative NAO phase (Figure 6), which had the effect of blocking the westerly storm track and diverting precipitation-bearing systems south across the Mediterranean. The East Atlantic / West Russian pattern remained slightly negative throughout the 1962-64 drought (Figure 6), which would have had the effect of reducing the severity of the winter rainfall deficit periods over southern Europe.
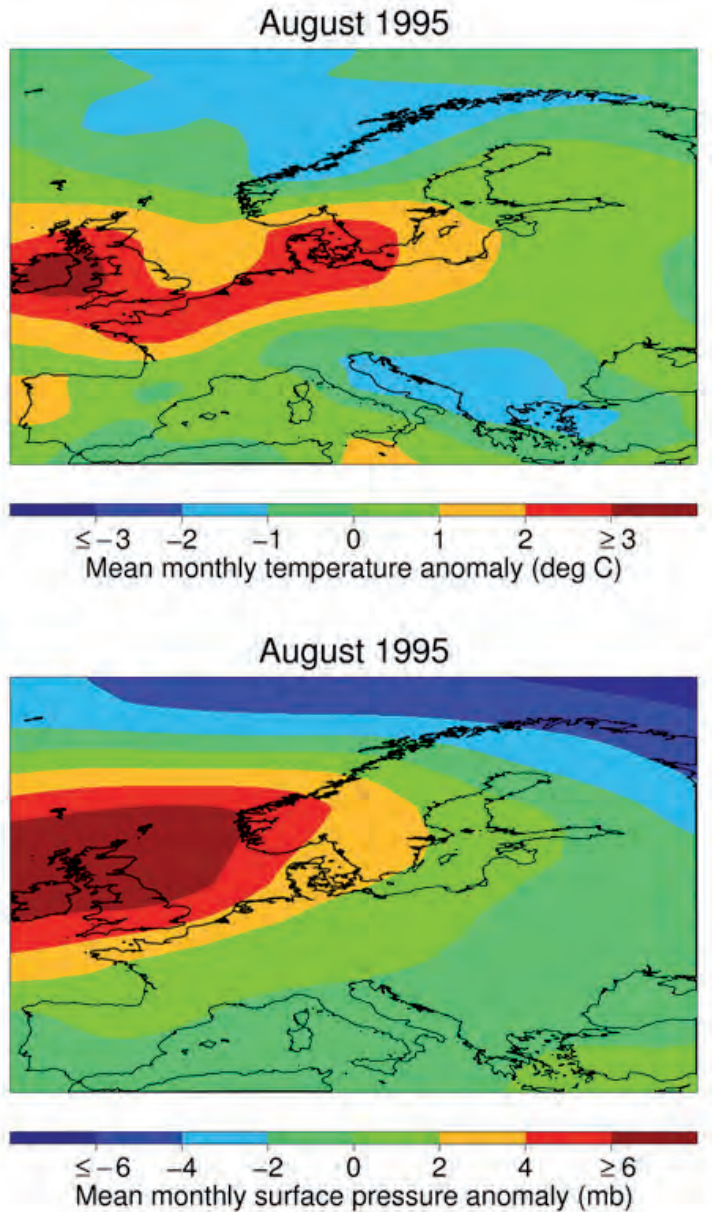

Figure 5 Temperature and pressure anomalies for the 1962-64 and the 1995-97 droughts. Derived from gridded National Centers for Environmental Prediction (NCEP) / National Center for Atmospheric Research (NCAR) reanalysis data. 

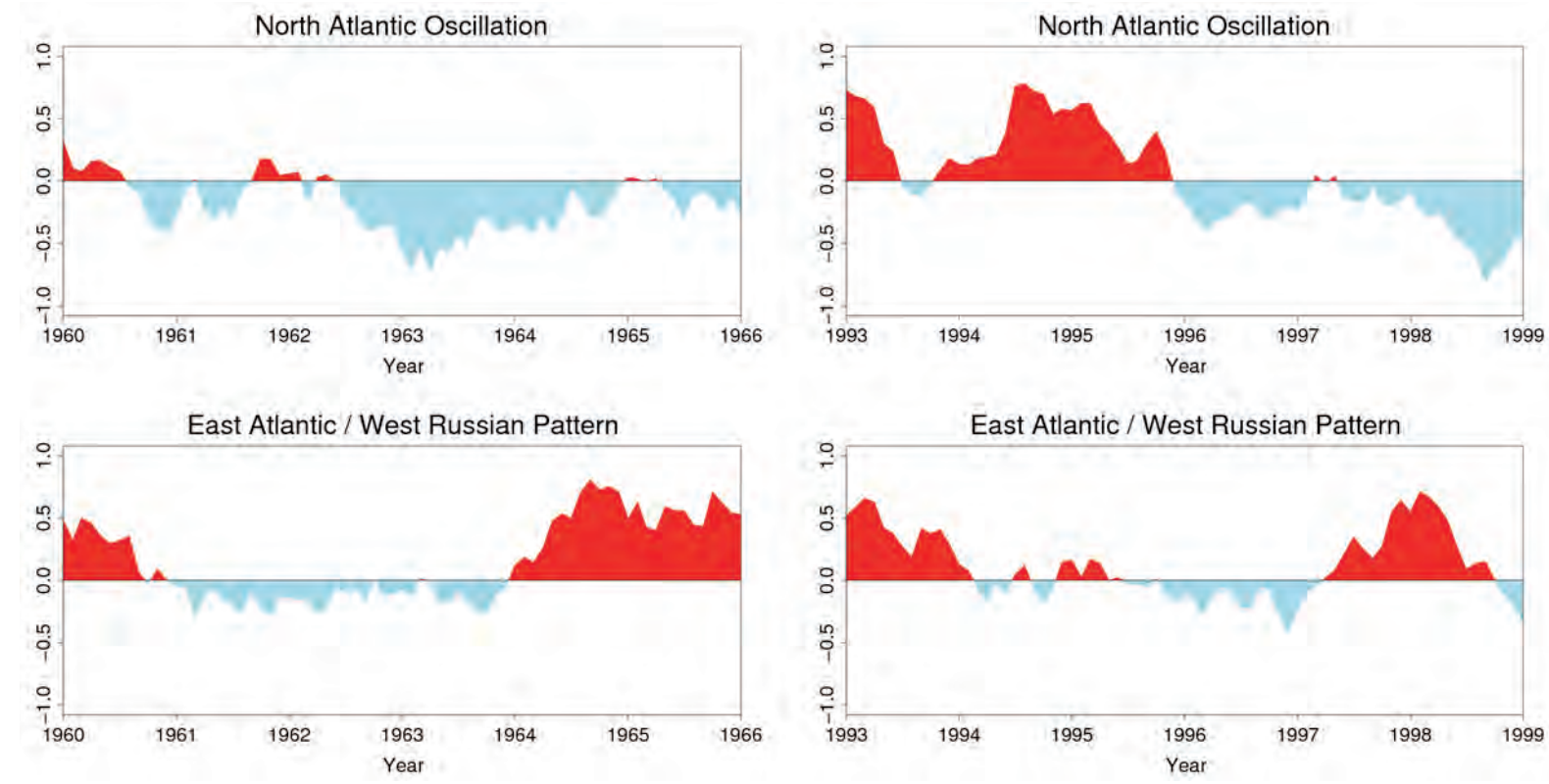

Figure 6 North Atlantic Oscillation (NAO) and East Atlantic / West Russian (EA/WR) pattern plots for the 1962-64 and the 1995-97 droughts.

\section{The 1995-97 Drought}

\section{Spatio-temporal evolution}

Whilst the majority of deficiencies during the 1995-97 drought were of limited spatial expression and coherence on a regional basis, there were some periods of severe continentalscale drought. The hydrological drought lagged behind the meteorological drought, which developed in western Europe during early/mid 1995, although streamflow deficiencies did not appear until the autumn and were restricted to the UK, with most regions registering coherent drought (RDI > 0.7; see Figure 3) in August 1995 (see Aug 1995 map in Figure 4) and little concurrent response on the continent. The lack of spatial coherence on a European scale can be attributed to the relatively localised impact of heatwave-dominated drought over the UK.

A relatively coherent phase of the drought, characterised by moderate deficits $(\mathrm{RDI}=0.5-0.6)$ expanded through Denmark, northern Germany and northern France during winter 1995/96, culminating in moderate spatial coherence across much of north-central Europe in April 1996 (see Apr 1996 map in Figure 4). This phase of the 1995-97 drought weakened through central Europe into the summer and the remainder of 1996 can be characterised by the prevalence of a comparatively wet interlude, although September saw some abrupt and short-lived deficiencies in Scandinavia and the UK (see Sep 1996 map in Figure 4), the latter of which had witnessed gradual drought development from eastern regions throughout the summer. Whilst the winter of 1996/97 was dry, only January 1997 was affected by moderately coherent drought, and only then in the UK and Scandinavia once more. Following a brief cessation in February and March, a spatially-extensive drought phase emerged in April with RDI > 0.5 across Spain, France and parts of the UK (see Apr 1997 map in Figure 4), although this began to diminish and weaken into central Europe through spring. The remainder of 1997 is characterised by spatially extensive drought but which lacked regional coherence (RDI values generally $<0.5)$; deficits were diffuse and highly variable in their distribution, although in the UK deficit conditions persisted throughout 1997. High RDI values remained throughout the summer into autumn in the southeast regions, with the groundwater-dominated catchments again exhibiting a greater persistence of periods of deficiency.
The 1995-97 drought had many significant environmental and socio-economic impacts. The shortduration, heatwave-dominated phase in summer 1995 had important adverse effects on those areas of the UK dependent on surface water resources, such as the South West, North West, Yorkshire and Midlands regions. The use of mitigation measures was widespread in these locations, with 53 drought orders imposed and hosepipe bans common. Ecologically significant fish kills, such as 20000 in the River Trent, and agricultural losses were among the myriad of environmental impacts (Cole and Marsh, 2006), the latter amounting to $£ 180$ million, with concurrent losses in the retail sector of $£ 380$ million and the cost of additional provision of water totalling £96 million (Palutikof et al., 1997). As with the 1962-64 drought, perhaps one of the most significant impacts of the 1995-97 drought was to encourage a change in attitudes towards water resources management in both the public and private sectors of the water industry. Improvements in the strategic infrastructural network and supply mechanisms were implemented as a direct result of public resentment over water shortages in Yorkshire and the North West in 1995 (Cole and Marsh, 2006).

\section{Temperature and pressure anomalies}

The 1995-97 episode began phenomenally, with summer 1995 registering as the third warmest on record in the UK and the driest since the benchmark drought of 1975-76, predominantly driven by high pressure located over the UK (Figure 5). The deficit conditions generated by high temperature and pressure anomalies in summer 1995 were exacerbated by the cold winter of 1995/96 that followed, although this was driven instead by a blocking high located over Scandinavia. Finally, high pressure formed over the North Sea in winter-spring 1996/97, similarly to the prevailing anticyclonic conditions responsible for the 1975-76 drought. These switches between different modes of circulation types during the 1995-97 drought episode are indicative of the complexity exhibited by multi-year, nonspatially coherent drought events.

\section{Synoptic climatic conditions}

The dominance of one mode of atmospheric circulation did not occur throughout the 1995-97 drought. The abrupt switch in the NAO from positive to negative is likely to 
have influenced the deficits observed in some northern areas in winter 1995/1996, and strongly indicates that this event was an amalgam of at least two smaller scale droughts. This is observed to a lesser degree in the EA/WR pattern the following year; the positive EA/WR anomalies may have been influential in the 1997 drought in western areas, although it could also be argued that the core years of the 1995-97 event were influenced by a slightly negative value of the EA/WR pattern.

\section{Discussion and conclusions}

The differences between the 1962-64 and 1995-97 droughts above have served to illustrate the complex variations in spatio-temporal evolution of European drought events. The 1962-64 drought can be predominantly characterised as a fairly straightforward succession of dry winters, which were generally coherent across the UK and Europe although the winter deficits varied in severity. The 1995-97 drought, on the other hand, was a more complex amalgam of both summer and winter periods of deficiency, which varied spatially and in terms of their extent, duration and spatial coherence. Just as there are examples of UK drought with no corresponding expression on the continent (e.g. 1984), there are as many instances of major continental episodes with no parallel deficits in the UK (e.g. the 1971/72 drought across most of continental Europe). In addition to a lack of pan-European spatial coherence between drought events, there are also variations in the extent to which the UK and Europe are 'inphase' or 'out-of-phase' with each other within major drought episodes.

When assessing each of the major European droughts in turn, it is clear that there are some commonalities between certain periods of each event, but it is also apparent that each has its own distinct spatial-temporal signature, despite being driven by qualitatively similar climatic conditions. This is a conclusion also reached by Lloyd-Hughes (in press), who applied the SPI within a new three-dimensional framework for analysing the spatio-temporal evolution of droughts, and found that assessing the event geometry of these 3-D structures yielded conclusions that drought events from 1901-2006 show significant dissimilarity, even amongst the most similar of episodes.

This study has been born out of the difficulties involved in deriving statistically significant relationships between drought parameters (Hannaford et al., in press), although this is at least partly attributable to the relatively short ( $\sim 50$ years) records being used that generate only five examples of spatially coherent, continental-scale droughts. The complexities involved in determining drought characteristics and evolution are also influenced by the driving synoptic climatic conditions and the more localised weather systems that follow. Although droughts are predominantly associated with significant pressure and temperature anomalies, they differ in their location and intensity between events, and a similar set of conditions has the potential to generate a number of different expressions of drought on the ground. Additionally, it has been shown that complex land-surface feedbacks may act to propagate drought conditions and potentially influence the spatio-temporal evolution, particularly so for notable droughts in the USA (e.g. the 1988 drought; Trenberth and Branstator, 1992).

The two examples discussed in this paper show the spatial coherence of drought in Europe on a large-scale, despite noticeable differences in their development. This suggests that it might be possible to develop forecasting methods that predict 'drought from drought' and this remains an appropriate approach worthy of further investigation.
Hannaford et al. (in press) have explored mechanisms underpinned by this 'drought from drought' concept, using drought occurrence in neighbouring predictor regions as well as the RSPI meteorological drought index to predict the number of drought months in the next six months, a similar timescale over which hydroclimatic parameters have been forecast in the wider literature and one which would, if successful, be of significant utility to water resource managers and policymakers in the public and private sectors.

Additional avenues of future research may include the use of gridded runoff data and/or alternative climate data, as well as other indices for characterising hydrological and meteorological drought. An additional option is to increase the sample size of major drought events analysed for common patterns that may lead to a forecasting technique by extending analyses of major drought events into the first half of the twentieth century. Compositing techniques may also help to identify common weather patterns associated with European droughts. The increased prevalence of anticyclonic conditions and the weather types that dictate their occurrence under drought conditions (e.g. Fleig et al., in press) suggest that a weather type approach may be suitable for consideration in underpinning a predictive forecasting model, although further research would be required before such techniques and relationships could be established.

\section{Acknowledgements}

The work presented in this study was initially a component of the 'Spatial Coherence of UK and European Droughts' project (SC070079), funded by the Environment Agency (EA) of England and Wales, and the Department for the Environment, Food and Rural Affairs (Defra). Additional funding arose from the European Union (EU; FP6) funded Integrated Project called Water and Global Change (WATCH) (contract number 036946), under the EU Sixth Framework Programme.

\section{References}

Briffa, K.R., Jones, P.D. and Hulme, M., 1994. Summer moisture variability across Europe, 1892-1991: An analysis based on the Palmer Drought Severity Index. Int. J.Climatology, 14, 475-506.

Cole, G.A. and Marsh, T.J., 2006. An historical analysis of drought in England and Wales. Climate Variability and Change - Hydrological Impacts (Proceedings of the Fifth FRIEND World Conference held at Havana, Cuba, November 2006), IAHS Publication No. 308.

Davies, A.W., 1978. Pollution problems arising from the 1975-1976 drought. Proc. Roy. Soc., London A, 363, 97-107.

Doornkamp, J.C., Gregory, K.J. and Burns, A.S. (eds.), 1978. Atlas of Drought in Britain 1975-76. Institute of British Geographers.

Fink, A.H., Brucher, T., Kruger, A., Leckebusch, G.C., Pinto, J.G. and Ulbrich, U., 2004. The 2003 European summer heatwaves and drought: synoptic diagnosis and impact. Weather, 59, 209-216.

Fleig, A.K., Tallaksen, L.M., Hisdal, H. and Hannah, D., in press. Regional hydrological drought in north-western Europe: linking a new Regional Drought Area Index with weather types. Hydrol. Process., in press.

Hannaford, J., Lloyd-Hughes, B., Keef, C., Parry, S. and Prudhomme, C., in press. Examining the large-scale spatial coherence of European drought using regional indicators of rainfall and streamflow drought. Special Issue of Hydrol. Process, in press. 
Lloyd-Hughes, B., Hannaford, J., Parry, S., Keef, C., Prudhomme, C. and Rees, H.G., 2010. Drought Catalogues for UK and Europe. Environment Agency Science Report SC070079/SR.

Lloyd-Hughes, B., in press. A spatio-temporal structure based approach to drought characterisation. Int. J. Climatol., in press.

Marsh, T.J., 2004. The UK drought of 2003: A hydrological review. Weather, 59, 224-230.

Marsh, T., Cole, G. and Wilby, R., 2007. Major droughts in England and Wales, 1800-2006. Weather, 62, 87-93.

McKee, T.B., Doesken, N.J., and Kliest, J., 1993. The relationship of drought frequency and duration to time scales. Proc. 8th Conference on Applied Climatology, 17-22 January. Anaheim, CA.: American Meteorological Society.

Mitchell, T.D. and Jones, P.D., 2005. An improved method of constructing a database of monthly climate observations and associated high-resolution grids. Int. J. Climatol., 25, 693-712.

Palutikof, J.P., Subak, S. and Agnew, M.D., 1997. Impacts of the exceptionally hot weather of 1995 in the UK. Proc. 10th Conference on Applied Climatology held at Reno, Nevada, USA, October 1997.

Parry, S., Hannaford, J., Lloyd-Hughes, B., Prudhomme, C. and Keef, C., 2010. Drought Summaries of Spatiotemporal evolution of major European Droughts since 1960. Environment Agency Science Report SC070079, Environment Agency, Bristol.

Prudhomme, C. and Sauquet, E., 2006. Modelling a regional drought index in France. CEH - Cemagref Joint Report. Centre for Ecology and Hydrology, Wallingford.

Stahl, K., and Demuth, S., 2001. Atmospheric circulation and drought. In: Demuth, S., and Stahl, K. (eds.) ARIDE Assessment of the Regional Impact of Droughts in Europe, 95-110. Institute of Hydrology, University of Freiburg.

Stahl, K., Hisdal, H., Tallaksen, L.M., van Lanen, H.A.J., Hannaford, J. and Sauquet, E., 2008. Trends in low flows and streamflow drought across Europe. Report to UNESCO.

Trenberth, K.E. and Branstator, G.W., 1992. Issues in Establishing Causes of the 1988 Drought over North America. J. Climate, 5, 159-172.

Zaidman, M.D. and Rees, H.G., 2000. Spatial Patterns of Streamflow Drought in Western Europe 1960-1995. Technical Report to the ARIDE project No.8.

Zaidman, M.D., Rees, H.G. and Young, A.R., 2002. Spatiotemporal development of streamflow droughts in north-west Europe. Hydrol. Earth Syst. Sci., 5, 733-751. 